\title{
Design and Optimization of Dual-Band Branch-Line Coupler with Stepped-Impedance-Stub for 5G Applications
}

\author{
Ayyoub El Berbri ${ }^{1, *}$, Adil Saadi $^{1}$, Seddik Bri $^{2}$ \\ ${ }^{I}$ Control, Pilotage and Supervision of Systems, National Graduate School of Arts and Crafts, Moulay Ismail University, Meknes, \\ Morocco
}

${ }^{2}$ Materials and Instrumentation, High School of Technology, Moulay Ismail University, Meknes, Morocco

Article history:

Received: 21 January, 2020

Accepted: 23 May, 2020

Online: 11 June, 2020

Keywords:

Optimization

Tuning

Dual-Band

Branch-Line Coupler
A B S T R A C T

This paper presents a design optimization of a dual-band branch-line coupler with steppedimpedance-stub lines. This coupler operates over $5 G N R$ frequency bands $n 5$ and $n 2$, developed by $3 G P P$ for the $5 G$ (fifth generation) mobile network, and these two bands are centered at $0.85 \mathrm{GHz}$ and $1.9 \mathrm{GHz}$ respectively. To achieve the design specifications an adjusted Tuning Space Mapping method is used. This method of optimization moves the hardship of optimization from high-fidelity electromagnetic models to low-fidelity tuning models. The simulated and measured results of this enhanced coupler show good dual-band performance at the two bands.

\section{Introduction}

The request for mobile communication is more than ever. For this reason, many researchers have focused on the development of a new generation of communication. $5 \mathrm{G}$ NR is a new radio access technology developed by 3 GPP for the $5 \mathrm{G}$ mobile network. We designed the coupler to function in the two bands $\mathrm{n} 5$ and $\mathrm{n} 2$ from the 3GPP TS 38.101 [1].

Branch-line couplers (BLC) offer a $\pi / 2$ power splitting and phase difference, which is suitable in different microwave circuits like power combined amplifiers, phase shifters, data modulators, and balanced mixers [2]. There are different dual-band BLC design that exists in the literature [3-9]. In this work, we use steppedimpedance-stub branches lines (SISBL) for dual-band operation. [10].

This work presents the design of a dual-band BLC with SISBL, designed for $5 \mathrm{G}$ NR frequency bands downlink [n2= $(0.869-0.894$ $\mathrm{GHz}) /(\mathrm{n} 5=(1.930-1.990 \mathrm{GHz})]$, this bands developed by 3GPP for the $5 \mathrm{G}$ (fifth generation) mobile network and centered at 0.85 $\mathrm{GHz}$ and $1.9 \mathrm{GHz}$ respectively [1].5G NR, like most modern techniques, demands height accuracy. In many situations like ours, due to microwave structure complexity of SISBL dual-band BLC,

*Ayyoub El Berbri, Moulay Ismail University \& ayyoub.elberbri@gmail.com the theoretical model only gives the initial design that requires optimization so he can meet the design specifications. In our case, for the optimization, we use an adjusted Tuning Space Mapping, the adjustment is made in the tuning model using our engineering expertise and knowledge of the design problem. The advantage is to reduce time-consuming. The enhanced characteristics of this Dual-Band BLC with SISBL are presented.

The simulated results of this enhanced dual-band BLC show good dual-band performances at $\mathrm{n} 5 / \mathrm{n} 2$. The performance of its fabricated prototype has also been validated experimentally.

\section{Dual-Band BLC with SISBL}

Figure 1 .a presents the SISBL containing a signal path $\left(Z_{3}, \theta_{3}\right)$ tapped with $\left(Z_{1}, \theta_{1}\right)$ and $\left(Z_{2}, \theta_{2}\right)[10]$. By multiplying the ABCD matrices of each cascade component, the ABCD matrix of the SISBL is reached. Since the dual-band branch line behaves as a $\pi / 2$ line at center frequencies of the two bands ( $\mathrm{f}_{\mathrm{p}}$ and $\mathrm{f}_{\mathrm{s}}$ ), the $A B C D$ matrix is formulated as (1).

$$
\left[\begin{array}{ll}
A & B \\
C & D
\end{array}\right]=\left[\begin{array}{cc}
0 & \pm \frac{j}{J} \\
\pm j J & 0
\end{array}\right]
$$


Where $\mathrm{J}$ the characteristic admittance of the $\pi / 2$ line

$$
x_{f}^{*}=\arg \min _{x} U\left(R_{f}(x)\right)
$$

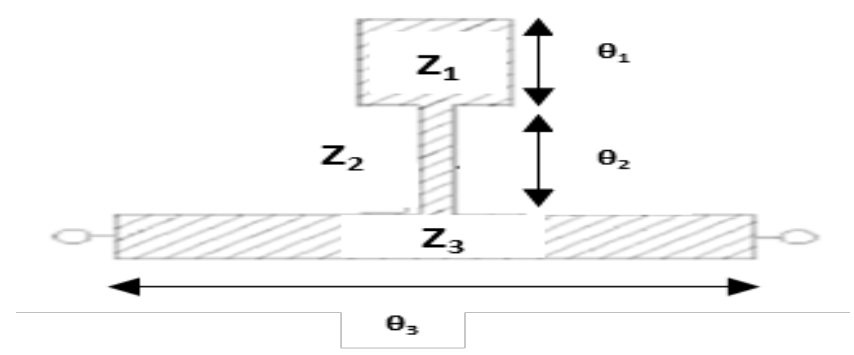

(a)

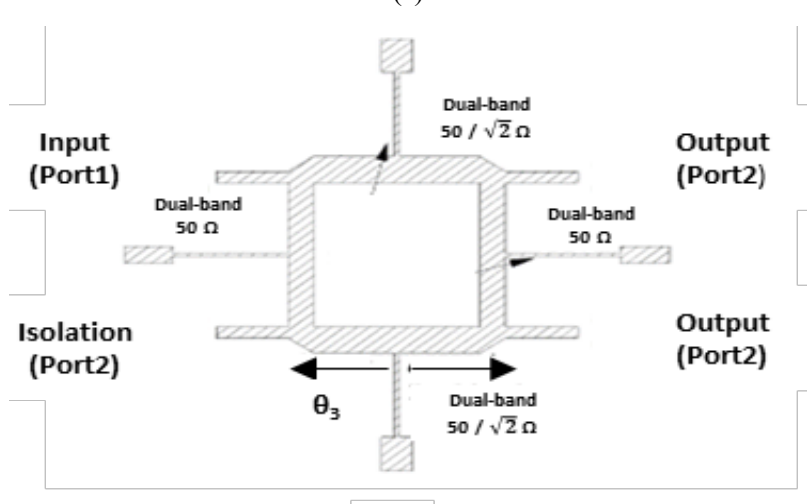

(b)

Figure 1. a: Dual-band SISBL; b: The dual-band BLC with SISBL.

The circuit dimensions of the SISBL Figure 1.b can be determined by solving the following equations (1)-(4). Where $\left(\theta_{1}\right.$, $\left.\theta_{2}, \theta_{3}\right)$ the electrical lengths of the lines $(1,2,3)$ respectively, and $\left(Z_{1}, Z_{2}, Z_{3}\right)$ the impedances of the lines $(1,2,3)$.

$$
\theta_{3}=\frac{2 n \pi}{\left(1+r_{f}\right)}
$$

where $\mathrm{n}=1,2,3 \ldots ; \mathrm{rf}=\mathrm{fs} / \mathrm{fp}$ is the frequency ratio.

To get a compact dual-band BLC in (2), $\mathrm{n}$ takes the value 1 .

$$
\begin{gathered}
Z_{3}=\frac{1}{J\left|\tan \frac{\theta_{3}}{2}\right|} \\
Z_{3} \cot \theta_{3}=\frac{2 * Z_{2}\left(Z_{1} \cot \theta_{1}-Z_{2} \tan \theta\right)}{Z_{2}+Z_{1} \cot \theta_{1} \tan \theta_{2}}
\end{gathered}
$$

We cast as free variables, the impedance ratio $R=Z_{1} / Z_{2}$ and the electrical length ratio $U=\theta_{1} / \theta_{2}$. Substituting (2)- (3), $Z_{1}=R * Z_{2}$ and $\theta_{1}=\mathrm{U}^{*} \theta_{2}$ into (4) eliminates $Z_{2}$, leads to (5):

$$
\tan \left[\theta\left(1+r_{f}\right)\right]=\frac{R\left[\cot \left(U \theta_{2}\right)+\cot \left(U r_{f} \theta_{2}\right)\right]}{1-R^{2} \cot \left(U \theta_{2}\right) \cot \left(U r_{f} \theta_{2}\right)}
$$

Equation (4) has only $\theta_{2}$ for variable since the constants $U, R$ and $r_{f}$ can be pre-chosen. $\theta_{2}$ is found using the graph of each side of the equation (4).

Figure 2 presents the variation of the impedances $Z_{1}$ and $Z_{2}$ versus frequency ration $\mathrm{r}_{\mathrm{f}}$ when $R$ and $U$ are both 0.2 . That figure shows that both $Z_{1}$ and $Z_{2}$ increase as $r_{f}$ increases. Since only an impedance of $20-120 \Omega$ can be realized using microstrip, the range of $\mathrm{r}_{\mathrm{f}}$ is limited to $1.9<\mathrm{r}_{\mathrm{f}}<2.5$.

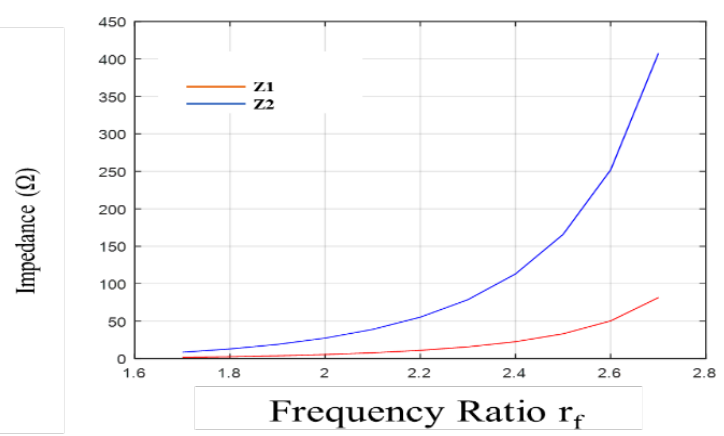

(a)

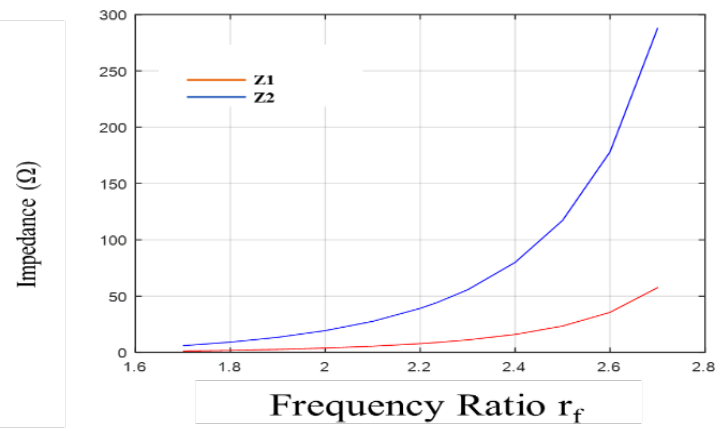

(b)

Figure 2: Variation of $Z 1$ and $Z 2$ versus rf. (a) Dual-band $50 \Omega$ branch line. (b). Dual-band $50 / \sqrt{ } 2 \Omega$ branch line

\section{Tuning Space Mapping}

The utilize of electromagnetic software for design optimization can be problematic, because EM simulations are rigorous. By shifting the optimization load onto a coarse model, for example, a circuit equivalent, space mapping (SM) reduces the computational rate of EM simulation. Over an iterative optimization and updating of the low fidelity models, SM achieves efficient optimization. [11].

Tuning space mapping such as SM belongs to a family of surrogate-based optimization techniques [12-23]. However, the role of the surrogate model is replaced by a so-called tuning model. By introducing tuning components (circuit-theory base components) into the fine model structure, the tuning model is built up. The original optimization problem is as follow [15]:

Where $\mathrm{R}_{\mathrm{f}} \in \mathrm{R}^{\mathrm{m}}$ is the response vector, $U$ is an objective function, $\mathrm{x}$ is the vector of design parameters, and $x_{f}^{*}$ is the optimal solution.

At $i$-th iteration, a tuning model $R_{t}^{(i)}$ is constructed based on the fine model data. The alignment process to eliminate the gap 
between the tuning model response and the response of the fine model at $i$, it is formulated as:

$$
x_{t, 0}^{(i)}=\arg \min _{x_{t}}\left\|R_{f}\left(x^{(i)}\right)-R_{t}^{(i)}\left(x_{i}\right)\right\|
$$

To fit the design specifications, $R_{t}^{(i)}$ needs to be optimized with respect to $x_{t}$. This is expressed by:

$$
x_{t, 1}^{(i)}=\arg \min _{x_{t}} U\left(R_{t}^{(i)}\left(x_{t}\right)\right)
$$

The modifications needed for the design variables are determined using a calibration process. Equation (9) express this process:

$$
x^{(i+1)}=C\left(x^{(i)}, x_{t, 1}^{(i)}, x_{t, 0}^{(i)}\right)
$$

\section{Results and Discussion}

We chose $(U, R)=(0.2,0.2)$, the dimensions of this dual-band BLC have been computed with the use of (2)-(5). Figure 3 illustrates the intersecting points of each side of the equation (4).

The length electric from Figure 3 is $\theta_{2}=72.68^{\circ}$. The other circuit dimensions $\left(Z_{1}, \theta_{1}, Z_{2}, Z_{3}, \theta_{3}\right)$ of both the $50 \Omega$ and $50 \Omega / \sqrt{ } 2$ branches of the coupler are computed from equations (2), (3) and (4).

The design parameters are $\mathrm{x}=\left[\begin{array}{lllllll}\mathrm{L}_{0} & \mathrm{~L}_{11} & \mathrm{~L}_{21} & \mathrm{~L}_{31} & \mathrm{~L}_{12} & \mathrm{~L}_{22} & \mathrm{~L}_{32}\end{array}\right]^{\mathrm{T}}$ $\mathrm{mm}$. The fine model, as shown in Figure 4, is simulated using a substrate of $\varepsilon_{\mathrm{r}}=4$, height $\mathrm{H}=1.4 \mathrm{~mm}$ and loss tangent $=0.0004$.

Figure 6 shows that $S_{11}$ and $S_{14}$ for the second band are below $-10 \mathrm{~dB}$ from $1.76 \mathrm{GHz}$ to $1.88 \mathrm{GHz}$, this is not the entire $[1.930$ GHz-1.990 GHz] band. And in the same range, the phase difference between output ports ( 2 and 3 ) is not $90^{\circ} \pm 10^{\circ}$. For better performance, optimization is needed.

To build the tuning model, we first simulate the fine model with the co-calibrated ports Figure 5, the corresponding S44P data file is charged into a 44-port S-parameter file component in the tuning model. After that, an appropriate circuit component is attached to the corresponding ports on the S-parameter component; the tuning parameters are $x_{t}=\left[\mathrm{Lt}_{0} \mathrm{Lt}_{11} \mathrm{Lt}_{21} \mathrm{Lt}_{31} \mathrm{Lt}_{12} \mathrm{Lt}_{22} \mathrm{Lt}_{32}\right]^{\mathrm{T}} \mathrm{mm}$.

The tuning parameters obtained after optimized the tuning

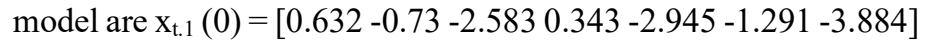
${ }^{\mathrm{T}} \mathrm{mm}$. With the use of a direct calibration the optimal values of the tuning parameters are converted to the adjustments of the design parameters in a direct manner. After the first iteration, the new design $\mathrm{x}^{(1)}=\left[\begin{array}{lll}50.9392 & 6.75824 & 38.710461 .27574 .4556638 .9794\end{array}\right.$ $51.5329]^{\mathrm{T}} \mathrm{mm}$ has already satisfied the design specifications Figure 7.

Figure 7 shows that the simulated $\mathrm{S}_{11}$ and $\mathrm{S}_{14}$ are less than $11 \mathrm{~dB}$, within the frequency range of $0.82-0.92 \mathrm{GHz}$ (first band), and within $1.88-2 \mathrm{GHz}$ (second band). Within a similar frequency range, the coupling coefficient is $3 \pm 1 \mathrm{~dB}$, the transmission coefficient is $3 \pm 1 \mathrm{~dB}$, and the phase difference between output ports (2 and 3 ) is $90^{\circ} \pm 10^{\circ}$. TABLE I summarized the performances of this dual-band BLC.

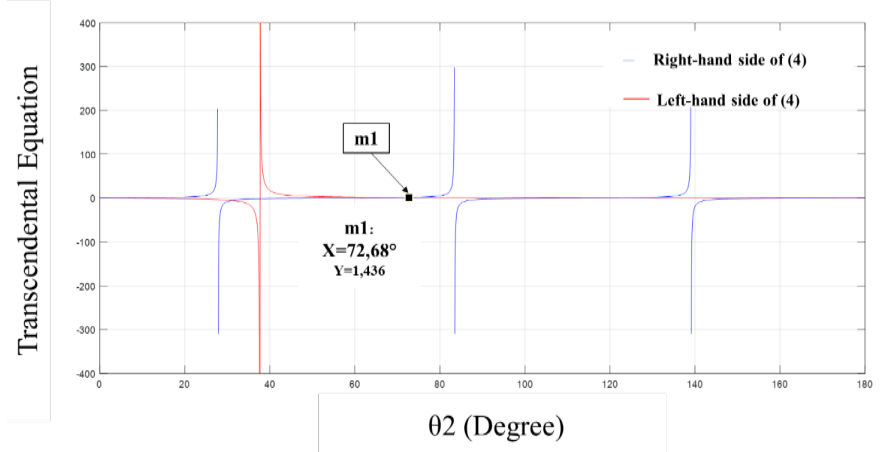

Figure 3: Solutions to (4) for $\theta 2$ of SISBL

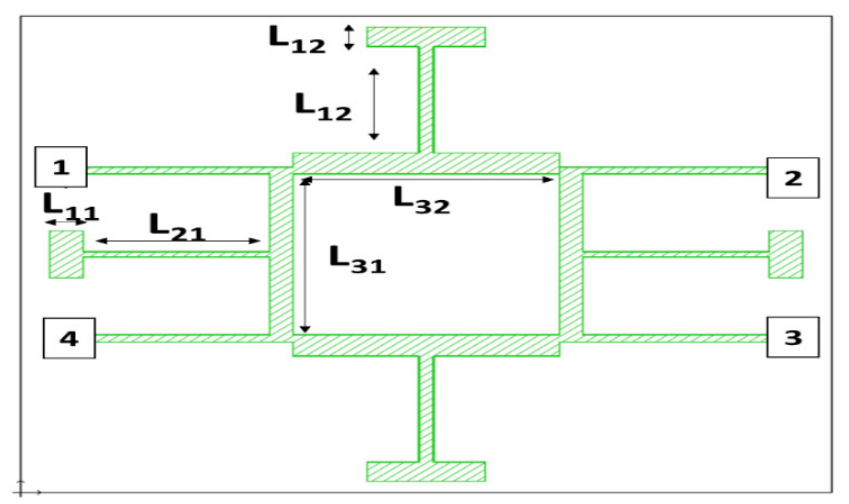

Figure 4: The fine model.

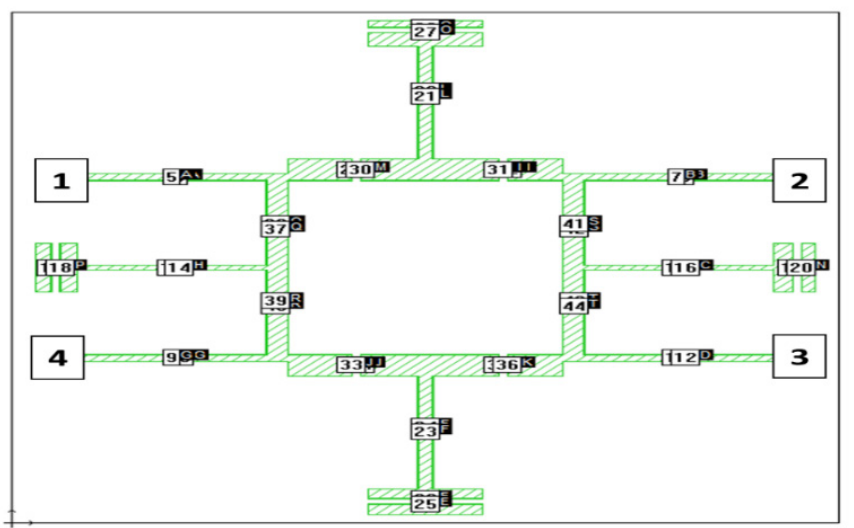

Figure 5: The fine model divided

Figure 8 shows the photograph of the prototype of the enhanced dual-band BLC fabricated using an LPKF machine. As we can see, its structure is relatively simple as it can be fabricated on a single layer printed circuit board with a simple ground plane.

The measurements of the fabricated prototype are done using 1-Port USB Vector Network Analyzer. Figure 9 plots the simulated and measured $\left(\mathrm{S}_{11}\right)$, it shows that there is a good match between simulated and measured $\mathrm{S}_{11}$ of this enhanced dual-band BLC.

TABLE I summarized, the results of the simulation for the initial and the optimized dual-band BLC performance, also the measurements of the fabricated prototype. The optimized dualband BLC shows better performances for both $5 \mathrm{G}$ NR bands, which the initial does not do. 

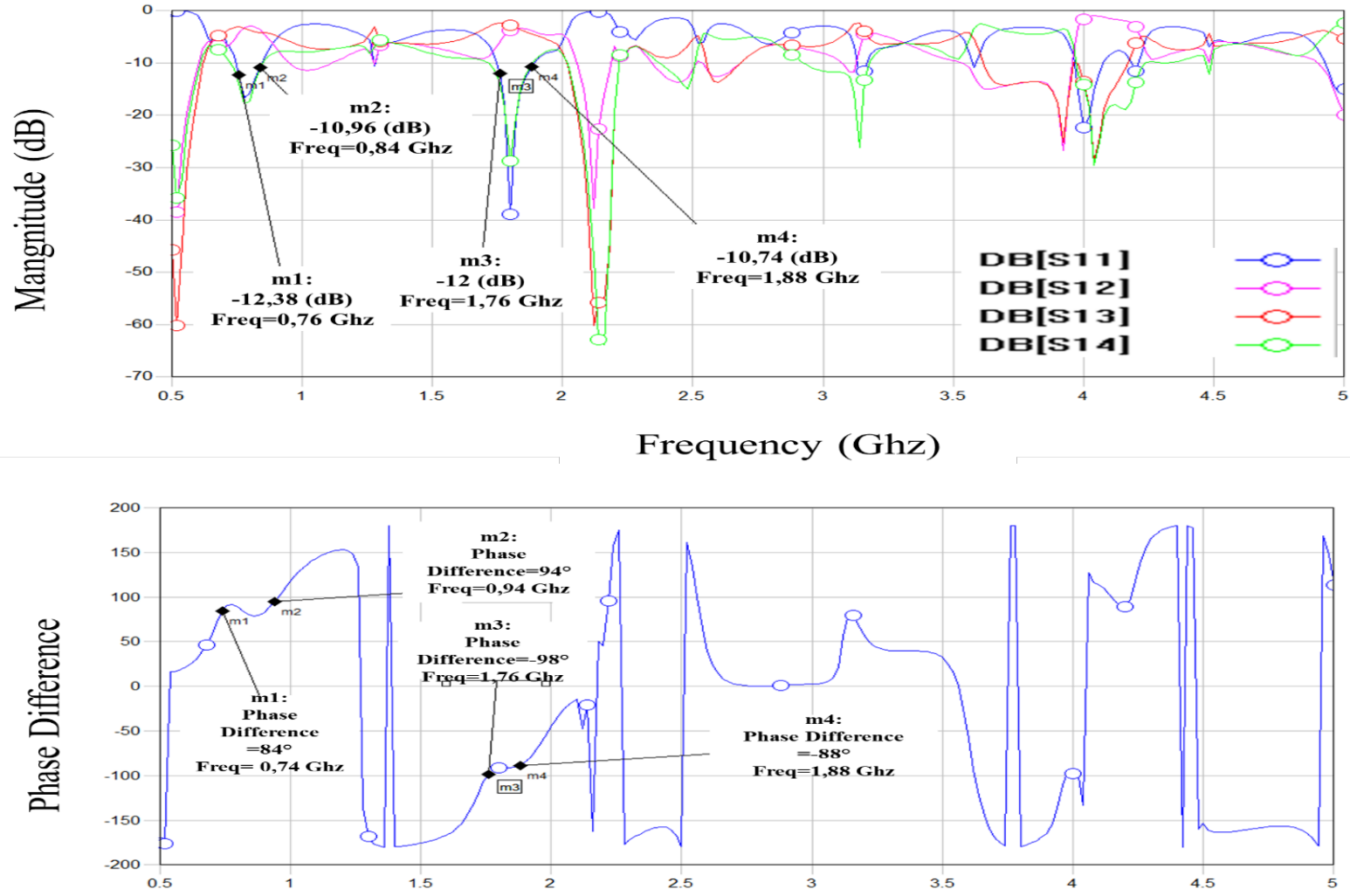

Frequency (Ghz)

Figure 6. The Initial fine model response; a:S-paramertres b: phase difference between Port2 and 3

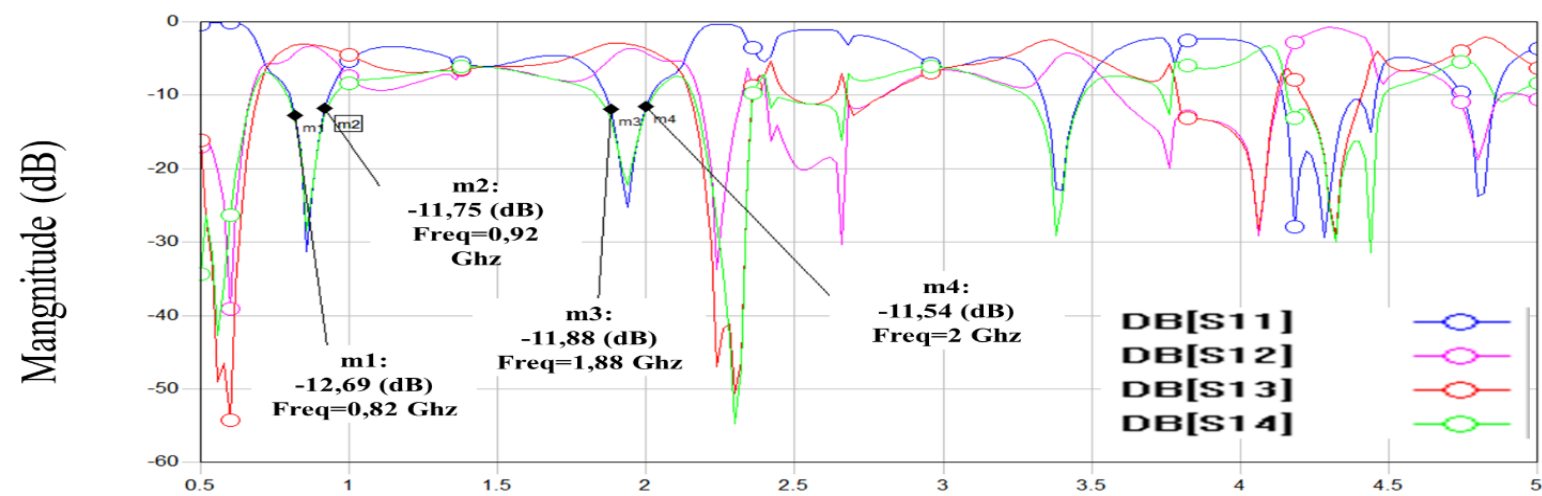

Frequency (Ghz)

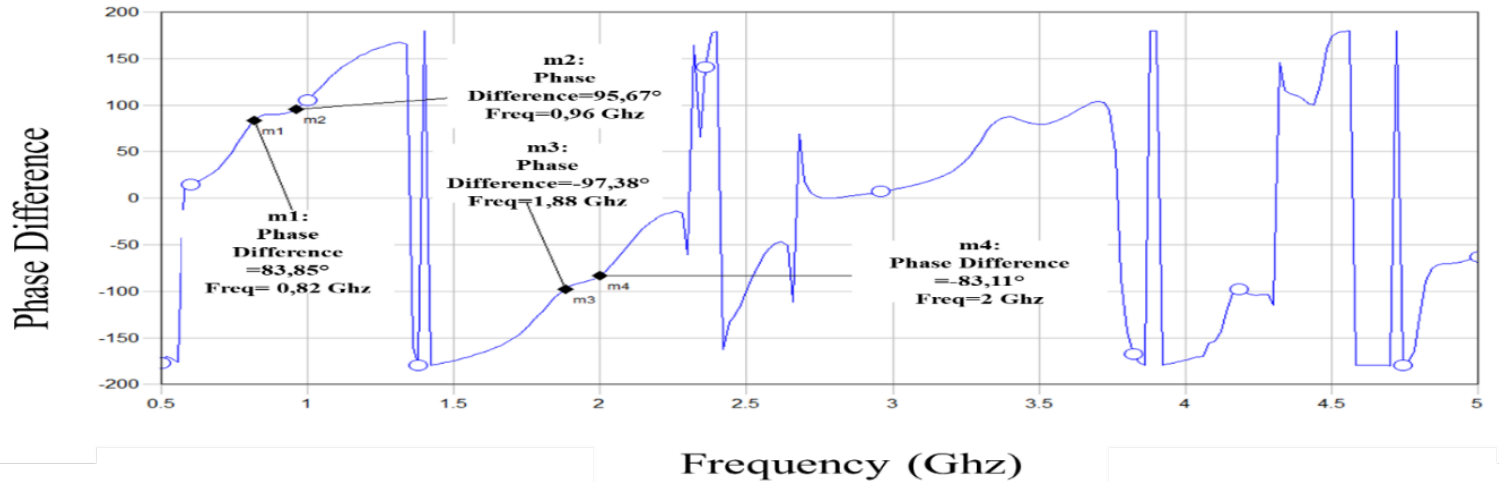

Figure 7: The Optimized fine model response; a:S-paramertres b: phase difference between Port2 and 3. 
Table 1: The simulated and measured results

\begin{tabular}{|c|c|c|c|c|c|c|}
\hline Parameter & $\begin{array}{c}\text { Initial } \\
\text { First band }\end{array}$ & $\begin{array}{c}\text { Initial } \\
\text { Second band }\end{array}$ & $\begin{array}{c}\text { Optimized } \\
\text { First band }\end{array}$ & $\begin{array}{c}\text { Optimized } \\
\text { Second band }\end{array}$ & $\begin{array}{c}\text { Measured } \\
\text { First band }\end{array}$ & $\begin{array}{c}\text { Measured } \\
\text { Second band }\end{array}$ \\
\hline $\mathrm{S}_{11}(\mathrm{~dB})$ & $<-10 \mathrm{~dB}$ & $<-10 \mathrm{~dB}$ & $<-10 \mathrm{~dB}$ & $<-10 \mathrm{~dB}$ & $<-10 \mathrm{~dB}$ & $<-10 \mathrm{~dB}$ \\
\hline $\mathrm{S}_{12}(\mathrm{~dB})$ & $3 \pm 1 \mathrm{~dB}$ & $3 \pm 1 \mathrm{~dB}$ & $3 \pm 1 \mathrm{~dB}$ & $3 \pm 1 \mathrm{~dB}$ & - & - \\
\hline $\mathrm{S}_{13}(\mathrm{~dB})$ & $3 \pm 1 \mathrm{~dB}$ & $3 \pm 1 \mathrm{~dB}$ & $3 \pm 1 \mathrm{~dB}$ & $3 \pm 1 \mathrm{~dB}$ & - & - \\
\hline $\mathrm{S}_{14}(\mathrm{~dB})$ & $<-10 \mathrm{~dB}$ & $<-10 \mathrm{~dB}$ & $<-10 \mathrm{~dB}$ & $<-10 \mathrm{~dB}$ & $<-10 \mathrm{~dB}$ & $<-10 \mathrm{~dB}$ \\
\hline $\begin{array}{c}\text { Phase } \\
\text { difference }\end{array}$ & $90^{\circ} \pm 10^{\circ}$ & $90^{\circ} \pm 10^{\circ}$ & $90^{\circ} \pm 10^{\circ}$ & $90^{\circ} \pm 10^{\circ}$ & - & - \\
\hline $\begin{array}{c}\text { Operating } \\
\text { frequency } \\
(\mathrm{GHz})\end{array}$ & $0.76-0.84$ & $1.76-1.88$ & $0.8-0.92$ & $1.88-2$ & $0.8-0.94$ & $1.84-2.04$ \\
\hline
\end{tabular}

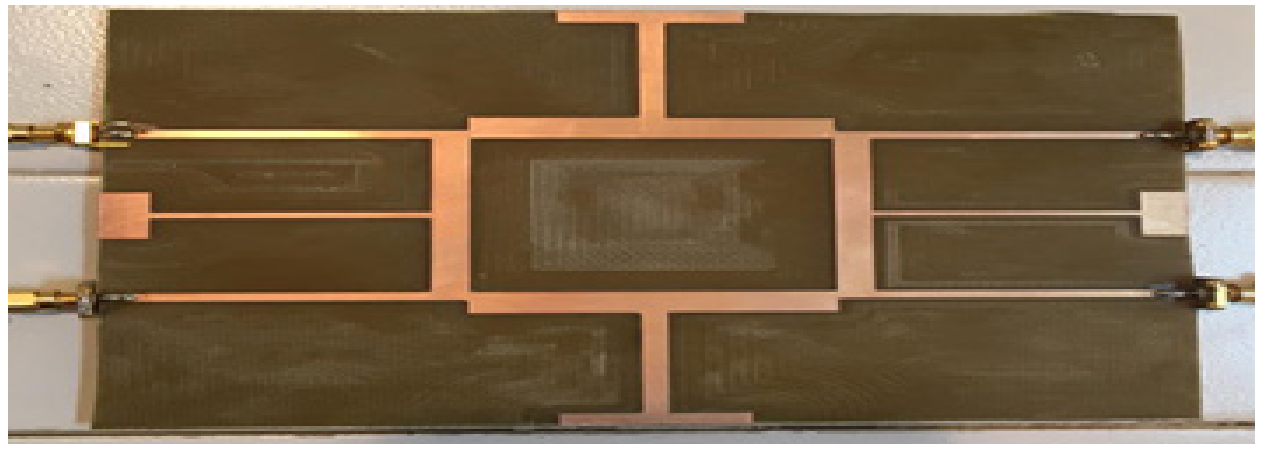

Figure 8: Photograph of the fabricated prototype

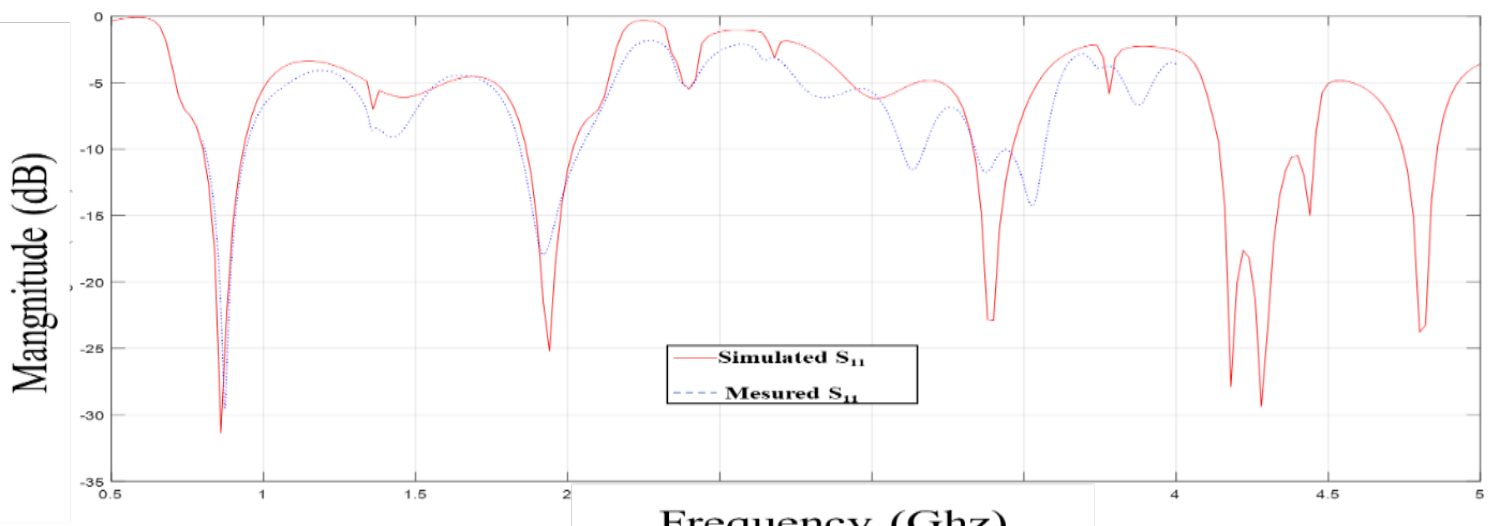

Frequency (Ghz)

Figure 9: simulated and measured $\mathrm{S}_{11}$

\section{Conclusion}

A dual-band BLC with SISBL for 5G NR applications has been designed. The coupler performance is further improved through optimization of his physical dimensions, using an adjusted Tuning Space Mapping to work for more complex microwave circuits such as our design. The simulated and measured results show that $\mathrm{S}_{11}$ are less than $-11 \mathrm{~dB}$, within the frequency range of 0.82-0.92 $\mathrm{GHz}$ (first band), and within 1.88-2 GHz (second band). The method used permits rapid optimization with accurate results obtained after only one iteration.

\section{References}

[1] 3GPP specification series: 38series.url: https://www.3gpp.org/DynaReport/ 38-series.htm (visited on 20/17/2020)

[2] D. M. Pozar, Microwave Engineering, 4th ed. New York: Wiley, 2012.

www.astesj.com
[3] M.-J. Park and B. Lee, "Dual-band, cross coupled branch line coupler" IEEE Microw. Wireless Compon. Lett., 15(10), 655-657, 2005. https://doi.org/10.1109/LMWC.2005.856683

[4] I.-H. Lin, M. DeVincentis, C. Caloz, and T. Itoh, "Arbitrary dual-band components using composite right/left-handed transmission lines" IEEE Trans. Microw. Theory Tech., 52(4), 1142-1149, 2004. https://doi.org/10.1109/TMTT.2004.825747

[5] J.-X. Niu and X.-L. Zhou, "A novel dual-band branch line coupler based on strip-shaped complementary split ring resonators" Microw. Opt. Technol. Lett., vol. 49(11), 2859-2862, 2007. https://doi.org/10.1002/mop.22873

[6] K.-K. M. Cheng and F.-L. Wong, "A novel approach to the design and implementation of dual-band compact planar 90 branch-line coupler" IEEE Trans. Microw. Theory Tech., 52(11), 2458-2463, https://doi.org/10.1109/TMTT.2004.837151

[7] C. Collado, A. Grau, and F. D. Flaviis, "Dual-band planar quadrature hybrid with enhanced bandwidth response" IEEE Trans. Microw. Theory Tech., 54(1), 180-188, 2006. https://doi.org/10.1109/TMTT.2005.860306 
[8] K.-K. M. Cheng and F.-L. Wong, "Dual-band rat-race coupler design using tri-section branch-line” Electron. Lett., 43(6), 41-42, Mar. 2007. https://doi.org/10.1049/el:20070018

[9] C.-L. Hsu, J.-T. Kuo, and C.-W. Chang, "Miniaturized dual-band hybrid couplers with arbitrary power division ratios" IEEE Trans. Microw. Theory Tech., 57(1), 49-156, 2009. https://doi.org/10.1109/ TMTT. 2008.2009036

[10] K.-S Chin, K.-M. Lin, Y.-H. Wei, T.-H. Tseng, Y.-J. Yang “Compact DualBand Branch-Line and Rat-Race Couplers with Stepped-Impedance-Stub Lines "IEEE Transactions on Microwave Theory and Techniques, 58(5), 2010. https://doi.org/10.1109/ TMTT.2010.2046064

[11] J. Meng, S. Koziel, J.W. Bandler, M.H. Bakr, and Q.S. Cheng, "Tuning space mapping: a novel technique for engineering optimization" in 2008 IEEE MTT-S International Microwave Symposium Digest, Atlanta, GA, USA, 2008. https://doi.org/10.1109/MWSYM.2008.4633001

[12] D. Echeverria, P.W. Hemker, "Space mapping and defect correction,"The International Mathematical Journal Computational Methods in Applied Mathematics, 5(2), 107-136, 2008. https://doi.org/10.1007/978-3-540$78841-68$

[13] M.A. Ismail, D. Smith, A. Panariello, Y Wang, and M. Yu, "EM-based design of large-scale dielectric-resonator filters and multiplexers by space mapping" IEEE Trans. Microwave Theory Tech., 52(1), 386-392, 2004. https://doi.org/10.1109/TMTT.2003.820900

[14] T.W. Simpson, J. Peplinski, P.N. Koch, and J.K. Allen, "Metamodels for computer-based engineering design: survey and recommendations" ENG. COMPUT., 17(2), 129-150, 2001. https://doi.org/10.1007/PL00007198

[15] J.W. Bandler, R.M. Biernacki, S.H. Chen, P.A. Grobelny, and R.H. Hemmers, "Space mapping technique for electromagnetic optimization" IEEE T. MICROW. THEORY., 42(12), 2536-2544, 1994. https://doi.org/10.1109/22.339794

[16] N.V. Queipo, R.T. Haftka, W. Shyy, T. Goel, R. Vaidynathan, and P.K. Tucker, "Surrogate-based analysis and optimization," PROG. AEROSP. SCI., 41(1), 1-28,2005.https://doi.org/10.1016/j.paerosci.2005.02.001

[17] S. Koziel, J.W. Bandler, A.S. Mohamed, and K. Madsen, "Enhanced surrogate models for statistical design exploiting space mapping technology" in IEEE MTT-S International Microwave Symposium Digest, Long Beach, CA, USA, 2005. https://doi.org/10.1109/MWSYM.2005.1517012

[18] S. Koziel, J.W. Bandler, and K. Madsen, "Theoretical justification of spacemapping-based modeling utilizing a data base and on-demand parameter extraction" IEEE T. MICROW. THEORY., 54(12), 4316-4322, 2006. https://doi.org/10.1109/TMTT.2006.884648

[19] S. Koziel and J.W. Bandler, "Microwave device modeling using spacemapping and radial basis functions" in 2007 IEEE/MTT-S International Microwave Symposium, Honolulu, HI, 2007. https://doi.org/10.1109/MWSYM.2007.380079

[20] V.K. Devabhaktuni, B. Chattaraj, M.C.E. Yagoub, and Q.-J. Zhang, "Advanced microwave modeling framework exploiting automatic model generation, knowledge neural networks, and space mapping" IEEE T. MICROW. THEORY., 51(7), 1822-1833, 2003. https://doi.org/10.1109/MWSYM.2002.1011836

[21] A. SAADI, S. BRI," Non-Linear Optimization of Small Size Microwave Directional Coupler Design Using Implicit Space" Int. J. Microw. Appl., Volume 2(4), 2013. http://warse.org/pdfs/2013/ijma022420 13.pdf

[22] F. Feng; C. Zhang; W. Na; J. Zhang; W. Zhang; Q.-J; Zhang, "Adaptive Feature Zero Assisted Surrogate-Based EM Optimization for Microwave Filter Design" IEEE MICROW. WIREL. CO., 29(1), 2-4, 2019. https://doi.org/10.1109/LMWC.2018.2884643

[23] B. Liu, V. Grout, A. Nikolaeva, "Efficient Global Optimization of Actuator Based on a Surrogate Model Assisted Hybrid Algorithm" IEEE T. IND. EL. $\begin{array}{llll}\text { CON. } & \text { IN., } & 65(7), & 5712-5721,\end{array}$ https://doi.org/10.1109/TIE.2017.2782203 